\title{
FEDERICO DE MADRAZO EN SEVILLA, 1858
}

\author{
por Montserrat Martí AyXelá
}

\begin{abstract}
En el presente artículo se aborda la interesante visita efectuada por el pintor madrileño Federico de Madrazo y Küntz (1815-1894), del que ahora se cumple el centenario de su muerte, a Sevilla en 1858, ocasión propicia para contactar con el ambiente artístico local, sobre el que influye notoriamente, al tiempo que para relacionarse con la corte de los Montpensier, representantes de la nobleza aristocrática sevillana que saben rodearse de una élite intelectual y sobre todo artística de primer orden.

Este rabajo constituye una interesante aportación al conocimiento de la Sevilla de los comedios del siglo XIX en sus aspectos sociales, culturales y artísticos vistos puntualmente a través de uno de los personajes más influyentes de la España decimonónica.
\end{abstract}

This work is a interesting contribution for the knowledge of the middle XIX century in you consideration social, cultural and artistic studiateds promptly / in a personality of Federico de Madrazo, the big spanish romantic painter.

Con motivo del centenario del fallecimiento de Federico Madrazo Küntz (1815-1894), creo sumamente interesante publicar las anotaciones inéditas de su agenda de bolsillo de 1858 en la que describió día a día su estancia en Sevilla en el mes de octubre de aquél año.

El primer dato referente a este asunto, es del día 28 de septiembre e indica que se dirigí a Palacio con su hermano Luís para ver al Rey y al día siguiente fue al Ministerio de Fomento para solicitar el correspondiente permiso de viaje para ausentarse de Madrid. Federico de Madrazo había sido nombrado profesor del dibujo del Antiguo y ropaje de los Estudios de la Academia en 1845, Primer pintor de Cámara en 1857 y ese mismo año profesor numerario de colorido y composición de los estudios superiores de la Escuela de Bellas Artes de San Fernando. El año de su viaje a Sevilla tuvo la gran satisfacción de ser nombrado por unanimidad Académico de la Insigne y Pontificia de San Lucas de Roma.

En la agenda de este año, Federico registró numerosas visitas a Palacio para entrevistarse con el Rey Francisco de Asís al que retrató en el mes de marzo. En las anotaciones de los meses siguientes escribe sobre las visitas diarias a Palacio con el fotógrafo Laurent, que califica de "inútiles". El objetivo era fotografiar a la Reina para poder realizar un retrato destinado a la embajada de Suecia. A su regreso de Sevilla siguí indicando estas visitas :"A palacio con Laurent para no 
hacer nada según antigua costumbre!" ${ }^{2}$. Finalizó el encargo en 1859, tras largas sesiones en las estancias de Isabel II. ${ }^{2}$

No indica en ningún momento el motivo del traslado a Sevilla pero es fácil suponer que tenía el compromiso de retratar a Cecilia Böhl de Fáber (Fernán Caballero) ${ }^{3}$ y que los duques de Montpensier deseaban hablar personalmente con él. Madrazo había retratado ya a los duques de Montpensier en diversas ocasiones. El primer retrato conocido es de la duquesa de 1846 como encargo de Mr. Guizot de París. Al año siguiente corresponden, así mismo, los retratos de $\mathrm{M}^{\mathrm{a}}$ Luisa Fernanda e Isabel II encargados por el duque de Montpensier y los del matrimonio, encargo del duque de Riansares. En 1850, Federico pintó un nuevo retrato del duque y al año siguiente fechó dos retratos de cuerpo entero de la pareja. En 1852 pintó en dos ocasiones a $\mathrm{M}^{\mathrm{a}}$ Amalia Enriqueta e Isabel Francisca Orleans de Borbón. En 1853 retrató nuevamente al duque y a su hija $\mathrm{M}^{\mathrm{a}}$ Cristina, en el 54 a Isabel Francisca, en 1859 a Francisco Orleans Borbón y en 1866 a su hermano Antonio. ${ }^{4}$

1. Madrazo, Federico de. Agenda de bolsillo, 3 de diciembre de 1858

2. El 17 de febrero llevó el retrato bosquejado a Palacio, el 28 vistió el maniquí de la soberana y durante los dos meses siguientes anota 25 sesiones en Palacio, finalizandolo el día 14 de abril. Según consideración del propio pintor, este retrato de Isabel II destinado a la Reina de Suecia, es uno de los más importantes pintados hasta 1871 . Federico de Madrazo pintó 28 retratos de la soberana entre 1842 y 1868 , según consta en sus escritos.

3. Nacida en Morges (Suiza) en 1796 y fallecida en Sevilla el 7 de abril de 1877. Instalada en Sevilla tras su segundo matrimonio con el marqués de Arco Hermoso, del que enviudó en 1835, volvió a contraer matrimonio con Antonio Arrom de Ayala, que falleció en 1859. Integrada en la vida y ambiente sevillano fueron sus años más fructíferos literariamente los que abarcan de 1849 a 1868.Asensio, José Ma ". Fernán Caballero: estudio biografico". Madrid: La España Moderna, (s.a.)

4. González López, Carlos, "Federico de Madrazo y Küntz", Editorial Subirana, Barcelona, 1981.

- Ma Luisa Fernanda, Ol.s.lzo. 65 x 53 cms. F., 1846. Encargo de Mr. Guizot. 1.500 reales. Col. Guizot, París. cat. 136

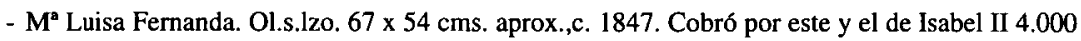
reales. Sanlúcar de Barrameda, col. Montpensier. cat. 155

- Ma Luisa Fernanda, Ol.s.lzo. 65 x $55 \mathrm{~cm}$ aprox.1847. 3.000 reales. París, col. Rjansares. cat. 156

- Duque de Montpensier. Ol.s.lzo. 66 x 54 cm. aprox. 1847 .Ovalado. París, col. Riansares. cat. 167

- Duque de Montpensier. Ol.s.lzo. 65 x $54 \mathrm{~cm}$. 1850. Patrimonio Nacional. Tesoro Artístico. Museo del traje. Palacio de Aranjuez. cat. 236

- $\mathbf{M}^{\mathrm{a}}$ Luisa Fernanda, 1851. Óleo sobre lienzo. 220 x $128 \mathrm{cms}$. Madrid, Palacio Real. Cobró 40.000 reales por este retrato y el de su esposo. cat.251

- Duque de Montpensier, 1851. Óleo sobre lienzo, 220 x $128 \mathrm{cms}$. Madrid, Palacio Real. cat.261

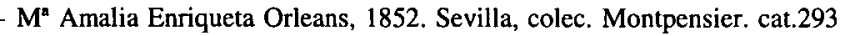

- Isabel Francisca Orleans, 1852. Ol.s.lzo.65 x 54 cms. Madrid. Descalzas Reales. cat. 294

- Isabel Francisca Orleans, 1852. Óleo sobre lienzo, 72 x 60 cms. Patrimonio Nacional. Palacio de Aranjuez. cat. 295

- Duque de Montpensier, 1853. cat. 327

- $\mathrm{M}^{\mathrm{a}}$ Cristina Orleans, 1853. cat. 328

- Isabel Francisca Orleans, Ol.s.lzo. 65 x 54,5 cms. 1854, col priv. Madrid. cat. 349

- Fernando Orleans, c. 1859. Sevilla col. Montpensier. cat .422 
Viajó a Sevilla con su hijo Raimundo que contaba 17 años y estaba estudiando en la Academia de San Fernando desde los catorce. Gracias a las meticulosas anotaciones que Federico escribía en sus agendas conocemos paso a paso el trayecto realizado desde Madrid a Sevilla. Partieron en el carruaje-correo y almorzaron en Manzanares. El día ocho de octubre escribió: " a las 11 en Sta. Cruz de Muida (navajas), a las 12 y 1/2 en Almoradiel, a la 1 y 29 en la Venta de Cárdenas (en ruinas) a las 3 y cuarto en Santa Elena, a las 4 en la Carolina y a las 6 y cuarto en Bailén".

El día 9 hicieron una cortísima visita a la mezquita de Córdoba a las 6 de la mañana, "a las 9 en la Carlota, a las 11 1/4 en Écija a las 9 1/2 en la Carmona (situada muy pintorescamente) llegando a las 9 1/2 de la noche a Sevilla", donde se hospedaron en el Hotel de Londres.

En su primer día de estancia en Sevilla visitó los domicilios de Joaquín Domínguez Bécquer (1817-1879), Fernán Caballero y Antonio de la Tour a los que no encontró, retornando por la tarde. Este último personaje, sabemos a través de las agendas de Madrazo que había acudido a su taller madrileño de la calle de la Greda, junto a los condes de la Unión y Vistahermosa. Concretamente le había visitado los primeros meses de este año siendo posible que fuera enviado por los duques de Montpensier. ${ }^{5}$

"Los Bejarano" les acompañaron al Museo del que hicieron un minucioso y amplio recorrido. ${ }^{6}$ Antonio Cabral Bejarano (1798-1861) ${ }^{7}$, era conservador del Museo Provincial, desde 1825, ayudante de perspectiva de la Escuela, director en 1850 y desde 1836 era académico de mérito de San Fernando. Su amistad con Madrazo era ya antigua y Federico cuando escribe "Los Bejarano", incluye a Manuel, Francisco y Rafael, hijos de Antonio. Federico estaba sumamente interesado en admirar las obras de Murillo, Valdés Leal, Zurbarán, Pacheco, Alonso Cano y Herrera el Viejo entre otros, de la entidad sevillana.

El día 11 recorrió el Alcázar con Bécquer, a las dos y media visitó a los Srs. Mora y posteriormente el domicilio particular de Bécquer. También la amistad con éste último, primo de José y tío de Valeriano y Gustavo Adolfo databa de hacía años, Bécquer era catedrático de Antiguo y Natural de la Escuela de Bellas Artes, Académico de Bellas Artes en Sevilla desde 1847, miembro de la comisión de conservación de Monumentos Artísticos, conservador y director de las obras de restauración del Alcázar de Sevilla y pintor de cámara desde 1850. Cercano a los duques de Montpensier, y preceptor y maestro de dibujo de sus hijos, pintó

\footnotetext{
- Antonio Orleans .c. 1866.Sanlúcar de Barrameda. Col .Montpensier. cat .455 Catálogo de los cuadros y esculturas pertenecientes al Palacio de SS.AA.RR. los serenisimos Infantes de España, duques de Montpensier. Sevilla, 1866

5. Antonio de La Tour, era preceptor de los hijos de los duques de Montpensier y vivía en el Palacio de San Telmo.

6. Madrazo, Federico de. Agenda de bolsillo, 1858. "Al Museo donde los Bejarano nos han enseñado todo"

7. La vida cotidiana en la pintura andaluza del S. XIX. Catálogo. Madrid. Nov:-Dic.,1987
} 
numerosos apuntes y dibujos para ellos. Retrató al duque ataviado con traje andaluz y a la duquesa en los jardines del Alcázar con su hija primogénita en brazos ${ }^{8}$. En 1857, pintó los retratos de Alfonso X, Pedro I y Doña $\mathrm{M}^{\mathrm{a}}$ Coronel y de 1859 son los de Fernando e Isabel la Católica. Estos retratos históricos sirvieron, posiblemente, de inspiración a Raimundo de Madrazo al que dos años más tarde le encargaron el retrato del Rey godo Ataulfo para la serie iconográfica de los reyes de España, formada en el Museo de pintura y escultura. ${ }^{9}$

En el taller de J. Bécquer trabajaba su sobrino Valeriano Domínguez Bécquer, me interesa especialmente este dato porque recientemente he localizado en una colección particular de Barcelona dos obras sumamente interesantes de este pintor, fechadas precisamente en este año 1858 . Se trata de dos retratos, uno de joven ataviada con traje de novia, y otro de dos niños. Valeriano mereció este año medalla de plata en la Exposición de Bellas Artes de Sevilla.

El arte del retrato en España estaba dominado por los pintores de la corte en Madrid. Recordemos que en este año dos retratistas sevillanos: José Gutiérrez de la Vega (1791-1865), profesor en la Academia de San Fernando y pintor de cámara y José $M^{a}$ Romero y López (c.1820-179) se encontraban en la capital de España, habiendo fallecido el año anterior Antonio $\mathrm{M}^{a}$ Esquivel (1806-1857). Desconozco datos concretos de la relación de estos pintores con Federico de Madrazo, pero es muy posible que tratara a menudo a Gutiérrez de la Vega en el Liceo Artístico de Madrid del que ambos eran asiduos.

Bajo el reinado de Isabel II persistió, en el ambiente oficial artístico madrileño la lucha entre las camarillas de los López y los Madrazo, iniciada tras la llegada a España de José de Madrazo. Ambos grupos representaban el arte áulico del retrato con acentuada influencia en los últimos de las tendencias desarrolladas en París y Roma, es decir búsqueda de belleza formal, predominio dibujístico, brillante colorido y serenidad compositiva. En mi opinión Valeriano estaba mas próximo, en esta época, a premisas características de Esquivel y de la escuela sevillana, concretamente en los fondos de los retratos, pero se pueden apreciar ciertos paralelismos con las obras de Madrazo. La postura de la figura femenina es la misma que la adoptada en diversas ocasiones por Federico para retratos de Isabel II. En la de Bécquer, el árbol hace el papel de los cortinajes clásicos y el apoyo de la retratada integra al personaje en el paisaje. A Madrazo no le interesaban excesivamente los fondos paisajísticos de referencia real ${ }^{10}$, prefería plasmar interiores con espacios abiertos hacia el exterior. Es interesante una comparación metodológica

8. Fechados ambos cuadros en 1847 , según indicación de Valdivieso. La hija primogénita, Isabel Francisca, fue bautizada en 1848, año indicado como el de llegada de los duques a Sevilla.

9. Actualmente dispersa por todo el país, pintaron para esta serie, los mejores pintores del momento, recordemos entre otros por su relación con los Madrazo a Bernardino Montañés Pérez, Germán Hernández-Amores, León Bonnat, Carlos $\mathrm{M}^{2}$ de Esquivel y Luis de Madrazo entre otros.

10. Son escasos los catalogados, destacando los de "Federico Flores" o "Agustina Larrañaga", el primero muestra un interesante paralelo con el retrato de Winterhalter del duque de Orleans, de 1842. Museo Nacional del castillo de Versalles. 
con otros grandes pintores áulicos como Franz Xavier Winterhalter (1805-1873) o Francesco Hayez (1791-1882) y constatar la similitud de actitudes adoptadas. En este sentido cabe exponer un cotejo entre el retrato de Valeriano Bécquer, el de la duquesa de Medinaceli de Madrazo del año 1854 y el de la duquesa de Montpensier de hacia 1847 de Winterhalter ${ }^{11}$. Los tres muestran a las protagonistas sobre fondo paisajístico con el cuerpo de tres cuartos y la mirada dirigida al espectador. He elegido estos tres ejemplos por su vinculación concreta con el mundo sevillano. Como he indicado anteriormente, Madrazo integra el paisaje situando al personaje en un interior abierto. A través de sus agendas de bolsillo hemos podido constatar que eran sus ayudantes los que en la mayoría de ocasiones pintaban los fondos de las composiciones, principalmente cuando se trataban de retratos oficiales.

Valdivieso destaca ya en las primeras obras de Valeriano un sólido dibujo y especial facilidad para el colorido. En un retrato infantil datado en 1850 resalta la capacidad en la captación de la psicología ${ }^{12}$. Este retrato infantil fechado en 1858 , es por factura e iconografía, característico del romanticismo, mostrando una actitud cotidiana de los retratados, acompañados de animales domésticos sobre un fondo paisajístico sumamente matizado y admitiría una comparación con el retrato de sus hijos pintado por Federico de Madrazo en 1854 o con el de los niños Desmaisieres de José Roldán.

Sevilla al igual que el resto de España conoció durante estos años y aún más concretamente a partir de 1858 con el gobierno de O'Donell, un auge económico en el que la oligarquía gobernante impuso un modo de vida cosmopolita a semejanza del de la alta burguesía francesa. La aparición de una nueva burguesía y la elección de Sevilla como lugar de residencia de familias oriundas de otras provincias españolas supuso un aumento de la producción artística de temas profanos destacando la demanda de retratos y paisajes.

El día doce, de nuevo con Bécquer de "cicerone", visitaron los departamentos de la catedral, destacando en sus anotaciones el retablo gótico de la Capilla Maese Rodrigo. Acudieron a la Caridad para admirar las obras de Murillo y de Valdés Leal, al patio de casa de los Abades y por último a La casa Pilatos propiedad de los Medinaceli. Estos residían en Madrid y como ya he indicado, Federico de Madrazo había retratado a la duquesa en 1854 y en 1860 retrató al duque con uniforme de maestrante de Sevilla.

Madrazo anota que conoció entonces a Roldán, se refiere al pintor José Roldán Martínez (1808-1871), profesor de dibujo de figura, representante de San Fernando en la Comisión de Monumentos. Principalmente retratista y pintor de temas

11. "Franz Xaver Winterhalter et les cours d'Europe de 1830 a 1870"; Catálogo. París, 1988., pág. 34, fig. 20. En las anotaciones del pintor referentes a los cuadros pintados, figura una copia de este, litografiada por L.Noël y de 1849, "La Duchesse de Montpensier, Paris, costume espagnol jusqu'aux genoux", en paradero desconocido y una repetición del mismo año. 218 x 149,5 cms. Versalles

12. Valdivieso, Enrique. "Pintura sevillana del siglo XIX", Sevilla, 1981 
costumbristas, pintó el año anterior de este viaje de Madrazo a Sevilla, el tema "La Caridad". Durante esta estancia en Sevilla se vieron constantemente y el día veintiséis Madrazo visitó el taller del pintor sevillano.

Los maravillosos tesoros de la Catedral hicieron que Madrazo repitiera la visita allí y al patio de la casa de los Abades. Con Bécquer y Boutelou (?), acudió a la Lonja, a la Giralda y a la Universidad a admirar los cuadros de Juan de Roelas. " $A$ Santa Paula, del tiempo de Doña Isabel, que tiene "preciosos azulejos y esculturas de porcelana, estilo Luca de Robbia firmadas por Nicolás Pissano". Visitó también la casa del duque de Alba, Palacio de las Dueñas, opinando: "muy curiosa y bastante arruinada". El día 14 acudió de nuevo a la Catedral, al museo y a casa de Cecilia Böhl de Faber, donde encontró a los Srs. Colón, Roldán y al escultor Leoncio Baglieto ${ }^{13}$ y por la noche asistieron a la ópera.

El quince, regresó a casa de F. Caballero con Varnhagen ${ }^{14}$ y a la de Bécquer, ubicadas ambas en el patio de Banderas. Con el último fue el día siguiente a Triana a la iglesia de Santa Ana para ver el retablo de quince tablas del ábside pintado por Pedro de Campaña y las obras de Alejo Fernández, interesándole especialmente "La Virgen de los Remedios".

Visitó de nuevo la biblioteca colombina, ubicada sobre el claustro de la Granada de la Catedral, buscando documentación para Raimundo, y el archivo de Indias. Al día siguiente, Madrazo se vio obligado a guardar cama debido a un cólico nefrítico, acudieron a visitarle al hotel: Bécquer, Álvarez, Manjarrés, Boutelou, Roldán, Cañaveral y Williams. ${ }^{15}$

El día dieciocho inició el retrato de Fernán Caballero en el estudio de Bécquer. Catalogado por Carlos González, es un ejemplo de lo que podríamos definir, dentro de la obra de Madrazo, como retrato de amigo, en los que predomina el sentido psicológico expresado a través de la mirada y la precisión de los contornos que quedan suavizados por una tonalidad integradora. En un escrito del pintor titulado "Acerca del retrato", Madrazo apuntaba la necesidad de conversar y conocer al retratado para poder expresar su carácter; las visitas a casa de la escritora, en los días anteriores al retrato, confirman esta convicción. Como curiosidad apuntaré, que Federico consideraba que todos los humanos guardamos similitudes fisiológicas con animales y que esta semejanza le facilitaba el resaltar ciertos rasgos de las facciones del rostro ${ }^{16}$.

13. Este año 1858 mereció medalla de plata en la Exposición de Sevilla por un busto de Murillo.

14. Se trataba posiblemente de Francisco Adolfo de Varnhagen. Historiador y diplomático brasileño, barón de Porto Seguro y secretario en Madrid de la legación de su país.

15. Desconozco la personalidad de Boutelou, Álvarez y Williams. Respecto a Manjarrés, se trata del escritor catalán José de Manjarrés y de Bofarull (1816-1880). Abogado y gran aficionado al arte, asistió a la Lonja entre 1841 y 1846 . Abandonó su carrera siendo nombrado en 1856 catedrático de teoría e historia de Bellas Artes con carácter interino. Años más tarde logró la plaza por oposición. Escritor y teórico cabría destacar de esta época la fundación de la revista "El Arte" que empezó a publicarse en 1859.

16. Madrazo, Federico de. "Memorias de mi vida", "Acerca del retrato". Archivo particular. 
Raimundo entretanto acudía diariamente al Museo para copiar a Murillo. El año anterior había pintado el tema "La traslación de los restos del Apóstol Santiago a la sede de Padrón" que expuso en la Regional de Sevilla. ${ }^{17}$ Este año, 1858, le encargaron un medallón decorativo para la Concepción Real de Calatrava. Actualmente el deficiente estado de conservación de los frescos impide una identificación y atribución. En mi opinión Raimundo pintó las pechinas de la bóveda y las lunetas de la fachada con temas religiosos referentes a la Virgen. ${ }^{18}$

Era la primera vez que viajaba a Sevilla y se entusiasmó por la luz y el ambiente además de cuajar importantes amistades. Apasionado por la fiesta taurina y por la ciudad, Raimundo viajó nuevamente a Sevilla en 1868 y en 1872. En el 68 fue acompañado por Mariano Fortuny al que mostró las bellezas de la ciudad e introdujo en los talleres de los pintores más relevantes. De entonces son varios temas, de ambos pintores, de temática taurina y vistas de la ciudad, que muestran por cromía y luminosidad el aspecto mas novedoso y natural de su obra. En 1872 se instaló una larga temporada, reuniéndose con Martín Rico y los pintores agrupados en Alcalá de Guadaira. En Sevilla se encontraba entonces, Irureta Goyena, amigo íntimo de Raimundo e importante coleccionista de obras suyas y del círculo de Fortuny.

Federico alternaba su trabajo en el taller de Bécquer donde pintaba los retratos de F. Caballero y de la esposa del pintor, con visitas a colecciones particulares y edificios públicos. Destacó en su agenda la colección de los herederos Cepero, una tabla de Luís Vargas en Santa M $^{\mathrm{a}}$ de la Blanca (Santa María de las Nieves), otra de Luis Morales en casa de Balmaseda, una "Concepción" de Pacheco en la parroquia de San Lorenzo y los cuadros del estudio de Cañaveral. Supongo debía ser el padre de José (1833-1894) y Alfonso (1860-1932), ambos estudiaron posteriormente en Madrid en el estudio de Federico de Madrazo, y José viajó a París por lo que tenemos noticias suyas a través de Raimundo de Madrazo. Por las memorias de Ricardo de Madrazo sabemos que Mariano Fortuny pintó en 1866 y en Madrid un retrato de "Cañaveral", ignorando de qué miembro de la familia se trata. Durante esta estancia en Sevilla fueron Raimundo y Federico los que retrataron a José Cañaveral ${ }^{19}$.

El día 24 ,acompañado de Donayre, Federico tuvo la oportunidad de poder contemplar detenidamente todas las obras de arte del Palacio de San Telmo, actuando de "cicerone", M. de la Tour y opinó "...cuadros antiguos y modernos muy notables".

17. Ossorio y Bernard, M."Galería Biográfica de Artistas españoles del siglo XIX, Madrid, 1975. Indica que lo expuso en Sevilla en 1868, rectificando nosotros esta fecha por la de 1858 a través de la documentación de los archivos de Madrazo.

18. En la fachada de la iglesia existe la inscripción:"Rex Franciscus Aedium frontem decoravit Munifice Anno 1858". Coincide con las fechas del encargo a Madrazo.

19. Ignoro el paradero y la iconografía de estas obras. Federico anotó en la agenda el día 14 de noviembre: "Estudio de Bécquer, retrato (busto) de Cañaveral". Comieron después en la pastelería Suiza. 
Antonio $\mathrm{M}^{\mathrm{a}}$ Felipe Luis de Orleans (1824-1890), casado el 10 de octubre de 1846 con $\mathrm{M}^{\mathrm{a}}$ Luisa Fernanda, hermana de Isabel II, se había instalado en Sevilla en 1848, tras la revolución de Francia. Había heredado de su padre el aprecio por las Bellas Artes y supo rodearse de pintores actuando de mecenas y formando a su alrededor una corte de artistas. Al igual que sus antecesores tenía un gusto especial por los retratos, entre otros destaco, además de los anteriormente citados de Federico de Madrazo, los pintados por Manuel Alonso de 1856, los de "familia" de Alfred Dehodenc o los de efemérides como "Presentación y bautizo de dña. $\mathrm{M}^{a}$ Isabel de Orleans y Borbón", 1849, de Rafael Benjumea, o el del mismo tema pintado por José $\mathbf{M}^{a}$ Romero. El duque había sido retratado en Francia por Winterhalter y Faure y Luisa Fernanda, de niña, por Antonio $M^{a}$ Esquivel y José Gutiérrez de la Vega entre otros. A la "corte sevillana" del duque acudieron el ya citado Dehodencq, Pharamond Blanchard, Adrien Dauzats, Barón Taylor, Ernest Laborde, J. Ch. Langlois y J.F. Lewis entre otros artistas extranjeros. Expertos grabadores, influyeron en los artistas sevillanos del momento, que en su mayoría pintaron encargos y retratos de la familia Montpensier. Antonio Cabral Bejarano había pintado en la Capilla de San Telmo por encargo del duque, un completo programa ornamental en el que también colaboraron sus hijos.

El día 25, Bécquer y Cañaveral, acompañaron a Madrazo a ver el "San Isidro" de Roelas que según Madrazo "tiene mucho de Tintoretto". Dos días más tarde con estos dos amigos embarcaron en el vapor rápido a Cádiz, donde acudieron al circo y al teatro en el que se representaba la zarzuela "Marina" Al día siguiente, tras visitar en la Catedral el "último cuadro de Murillo, Los despojos de Santa Catalina", viajaron a Jerez y Puerto de Santa María a ver una colección particular de la que le interesaron especialmente las obras de Guido Reni y de P. Pater (sic).

El 29 regresaron a Sevilla en coche de "colleras" y en los últimos días de este mes recorrió los jardines del Palacio de San Telmo, fue a la Sala de la Hermandad Sacramental del Sagrario a ver el cuadro "La disputa sobre el misterio de la Inmaculada Concepción" de Herrera el mozo y visitó las colecciones de Diego Suárez y del Sr. Larrazábal; "una Magdalena de Zurbarán, una Divina Pastora de Tovar y un S. Pedro de Gerdo. de la roche (sic)"

Inició el mes de noviembre estudiando los cuadros de la Sacristía de la Catedral, donde dibujó algunas estatuas de la fachada y visitó los restos árabes de Casa de Olea. También Raimundo pintaba en la Catedral ejercitándose en el dibujo de estatuas.

El día seis finalizó el retrato de Fernán Caballero y al día siguiente regresó a la Catedral y a San Telmo para entrevistarse con S.S.A.A. El motivo de esta visita era un encargo del Duque de Montpensier de un retrato de familia, para ello Federico visitó a los infantes y recorrió de nuevo los jardines de Palacio buscando un fondo idóneo para la composición. Los días siguientes del 9 al 14 se instalo 
en Palacio donde comenzó a dibujar y pintar estudios de la composición. Dibujó un retrato del "ama de cría con la Infanta menor en brazos". ${ }^{20}$

El día once de noviembre, Federico vivió las sacudidas del terremoto y al día siguiente acudió a la catedral donde se celebró un Tedeum por el suceso. El día 13 estuvo invitado a una comida en Palacio de la que escribió: "la comida ha estado brillante, habia unos 40 convidados, entre estos el Conde de la More".

Partió hacia Madrid el 18 de noviembre y los tres días anteriores los dedicó a recorrer casas y estudios para despedirse de sus amigos, en Palacio aprovechó para admirar "los hermosos álbumes de SS.AA". Desconozco si llegó a finalizar el retrato de familia de los duques de Montpensier ya que no figura en ninguno de los relaciones escritas por él mismo, y tampoco en el catálogo realizado por Carlos González. Respecto a este año Federico indicó que había pintado doce retratos cobrados y seis regalados ${ }^{21}$, Según Rogelio Buendía y por tradición familiar, el retrato de la esposa de Bécquer, se conserva actualmente en el Museo Romántico de Madrid ${ }^{22}$.

Otro dato interesante respecto a Federico de Madrazo y la ciudad de Sevilla es el apuntado por el pintor en un escrito datado en 1871 en el que indica que en el Palacio de San Telmo se encontraban su famoso cuadro: "La enfermedad del rey don Fernando" de 1832 y tres cuadros que había pintado para un techo de Vista Alegre referentes a la música y la armonía ${ }^{23}$.

Esta visita a Sevilla es significativa no sólo por los retratos pintados allí por nuestro artista, sino porque reforzó su relación con el ambiente artístico de la ciudad. Ya he indicado los contactos de Raimundo con los Cañaveral, Bécquer, etc, pero será la siguiente generación de artistas sevillanos los que estuvieron más estrechamente ligados a Raimundo y Fortuny, baste recordar los nombres de los hermanos Villegas y Jiménez Aranda, García-Ramos o Manuel Wssel entre otros, relacionados con la familia Madrazo en Roma y París ${ }^{24}$. Mariano Fortuny en el viaje a Sevilla en junio de 1870 , acudió, por recomendación de su suegro, al estudio de Joaquín Domínguez Bécquer. Ricardo de Madrazo, "portavoz" de

20. Podría tratarse de Joaquina Miranda o Ramona Castaño de Robles, ayas de la familia, y alguna de las infantas fallecidas por las aguas contaminadas de San Telmo.

21. Madrazo, Federico de. "Retratos que he pintado después de mi vuelta a España (1842) y que me han sido pagados. También van incluidos aqui alg. que he hecho en litografia, y dos o tres obras que no son retratos, y asi mismo los que he regalado". En la lista de regalados figuran: $n^{\circ} 96$. "Retr. con manos, de Fernán Caballero con mantilla- lo tiene el D. de Mont.", nº 97 "Sevilla, 1858, retr. busto, de D. José Cañaveral".

22. "Retrato de dama", Óleo sobre lienzo, 90 x $60 \mathrm{cms}$. Inv. n 2301. Museo Romántico. "Adquisiciones 1987-1992", Madrid, 1993. Ingresó el 3 de diciembre de 1990. Perteneció a la colección Buendía. En este catálogo aparece como obra anónima.

23. Madrazo, Federico de. "Títulos oficios y premios hasta 1871", sin foliar. Archivo particular.

24. González, Carlos-Martí Ayxelá, Montse. "Pintores españoles en Roma, 1850-1900", Barcelona, 1987. "Pintores españoles en París, 1850-1900", Barcelona, 1989. 
las opiniones de su cuñado, escribió a su padre: "que estaba haciendo un cuadro grande de la entrevista de O'Donell con Muley-el-Abas", del que suponemos el pintor catalán pudo dar detalles concretos por su conocimiento del tema. Existen muchos más datos del entusiasmo de Fortuny por Sevilla y de su aspiración a comprar una casa y fijar su residencia allí, deseo que desde luego merecía la aprobación y apoyo de Federico de Madrazo, pero que no pudo realizar al tener que regresar con urgencia a Roma y fallecer prematuramente en 1874 . 


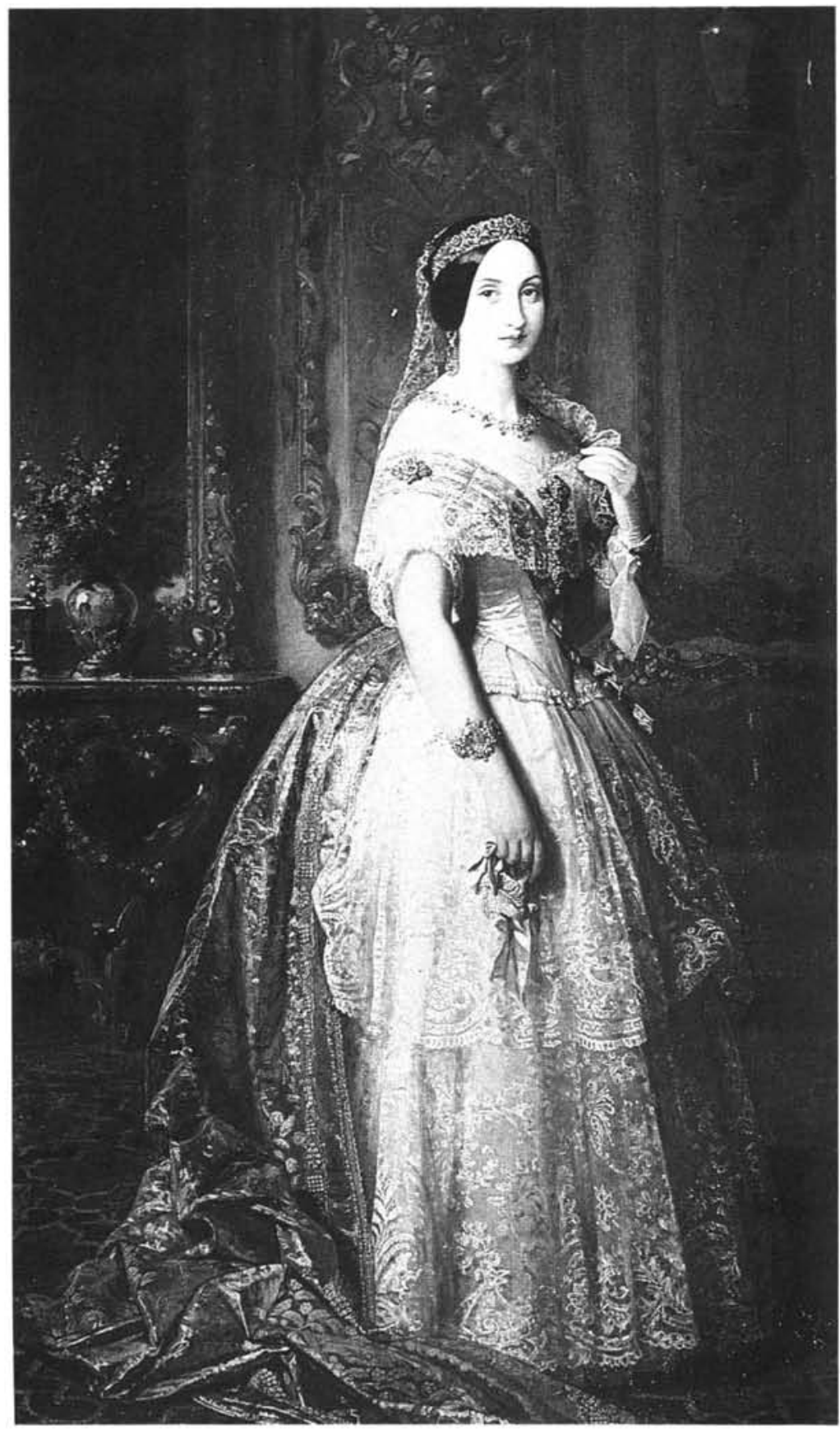

Foto 1: Federico de Madrazo. M² Luisa Fernanda de Borbón. Duquesa de Montpensier, 1851. Óleo sobre lienzo. Medidas: 220x128 cms. Patrimonio Nacional. Tesoro Artístico. Palacio de Oriente. 


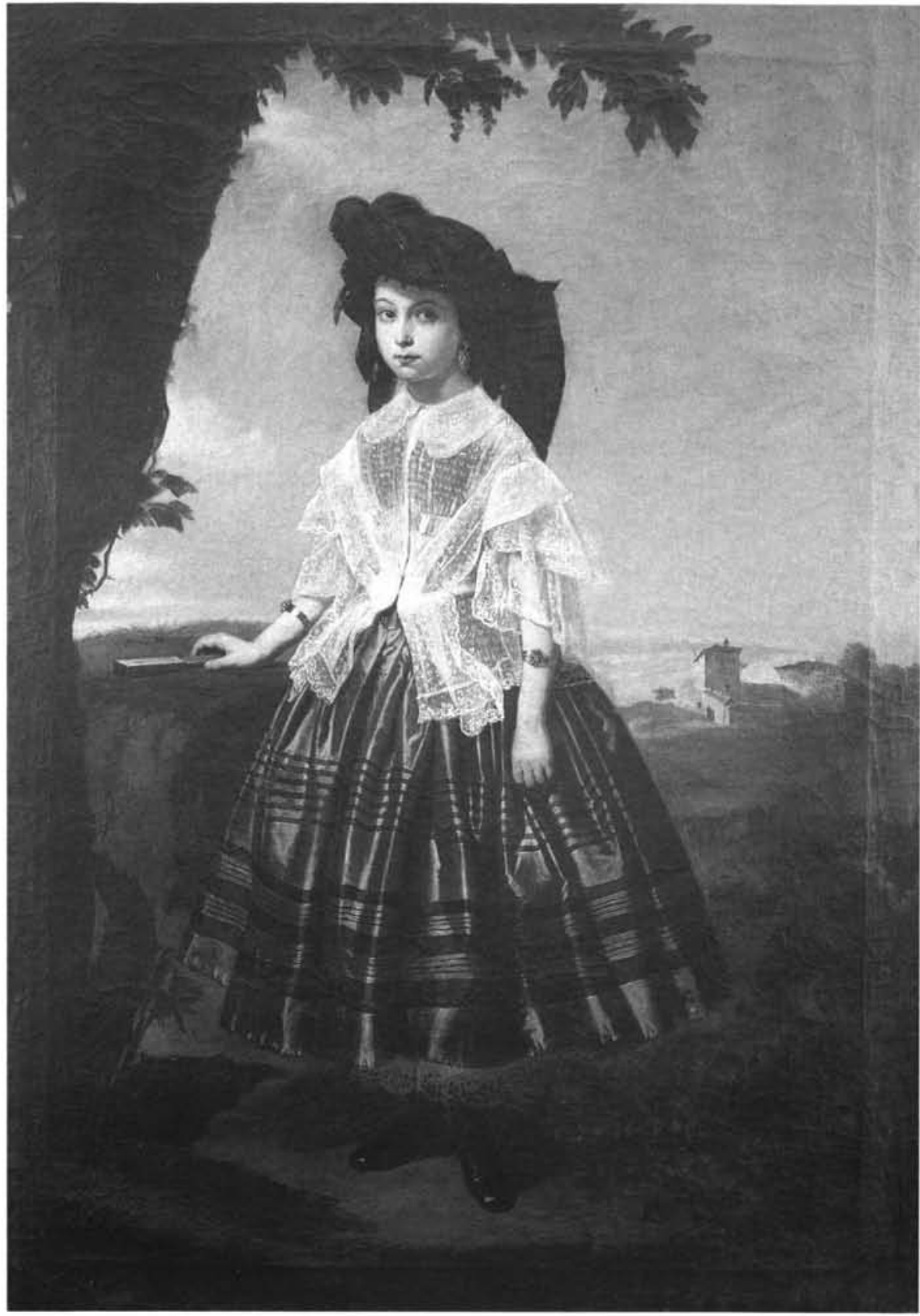

Foto 2: Valeriano Domínguez Bécquer. Retrato femenino, 1858. Óleo sobre lienzo. Medidas: 150x106 cms. 


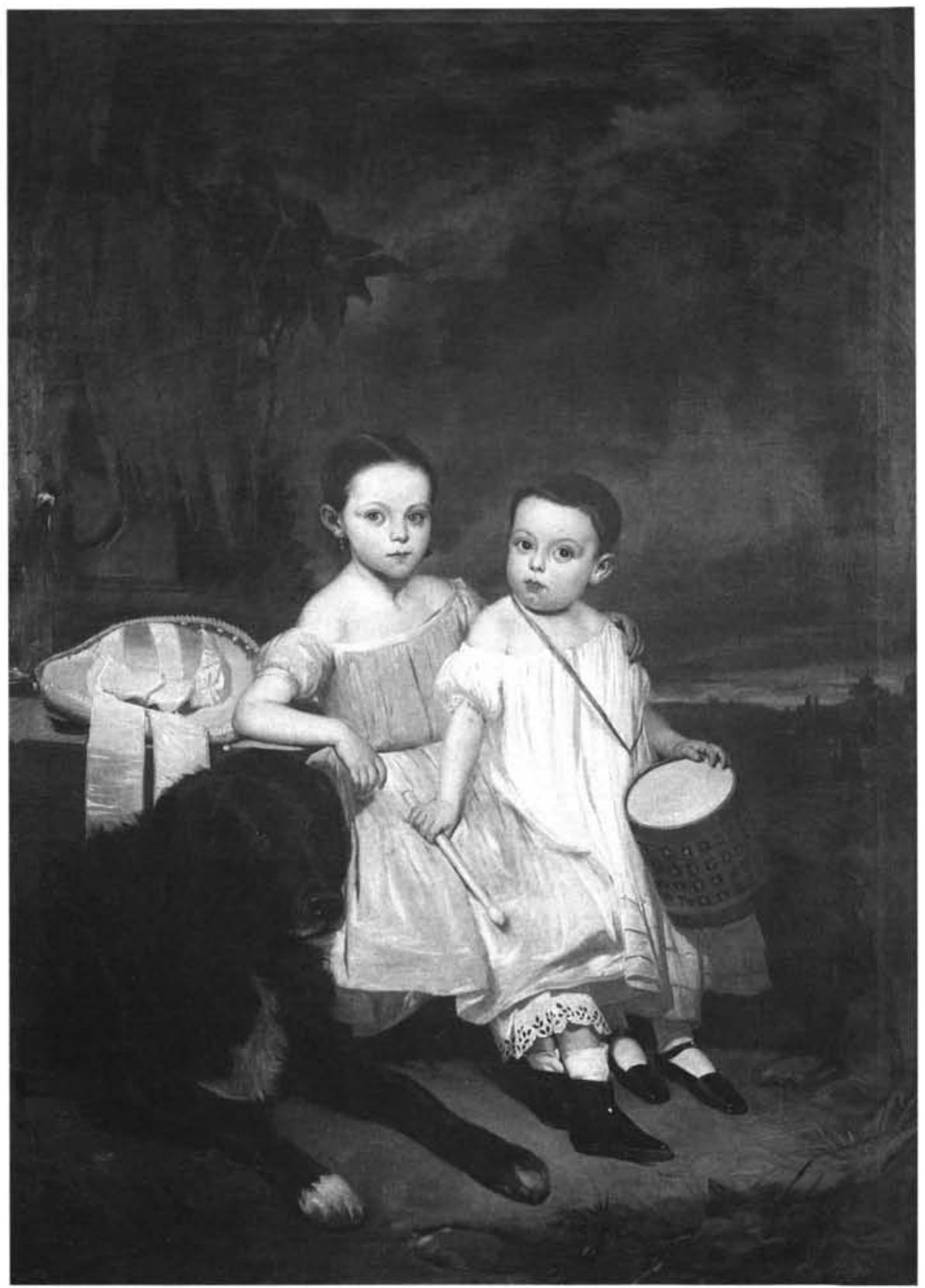

Foto 3: Valeriano Domínguez Bécquer. Retrato infantil, 1858. Óleo sobre lienzo. Medidas: $150 \times 108 \mathrm{cms}$. Colección particular. 


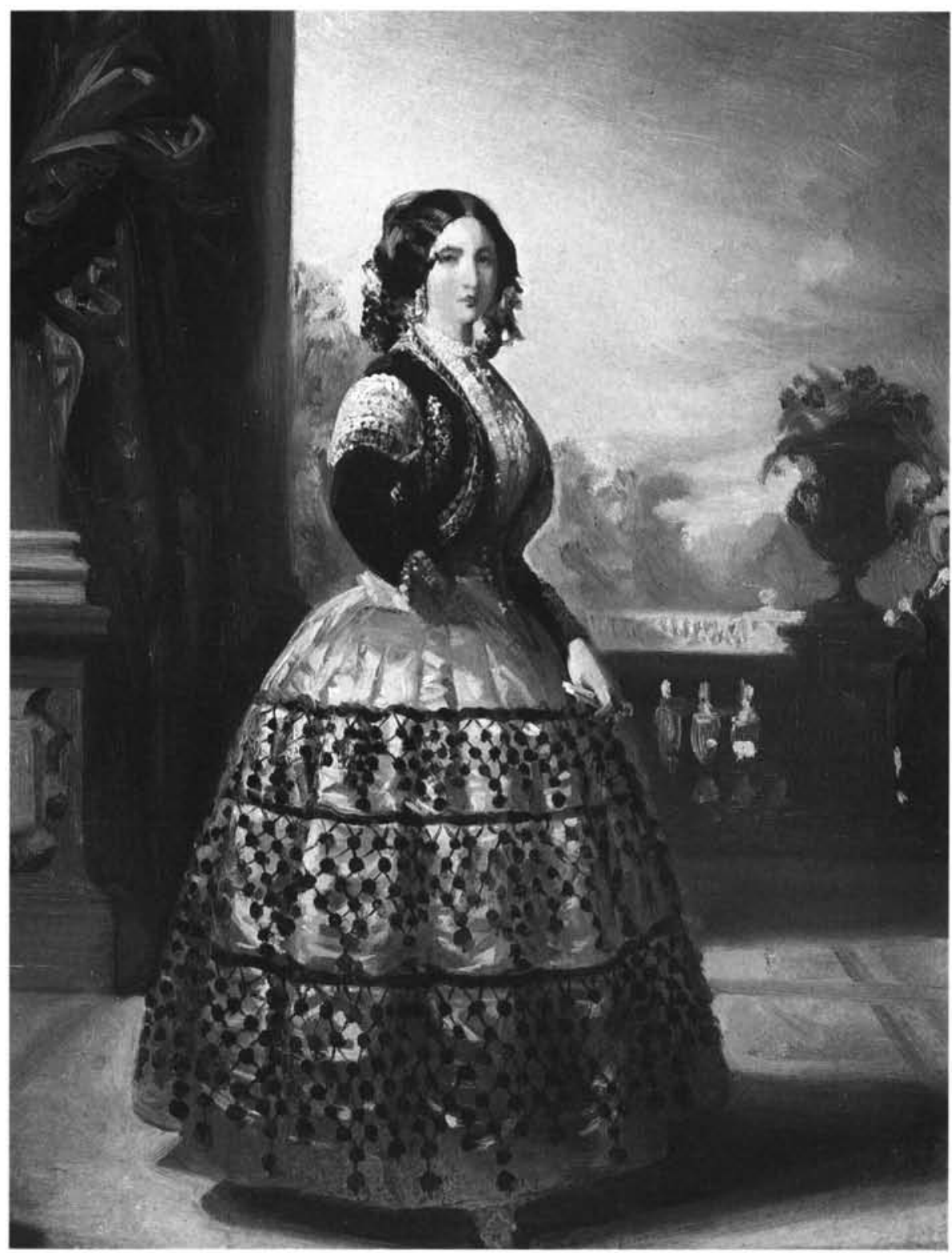

Foto 4: Federico Madrazo. Duquesa de Medinaceli. c.1854. Óleo sobre tabla. Medidas: 35×26 cms. Colección particular. 


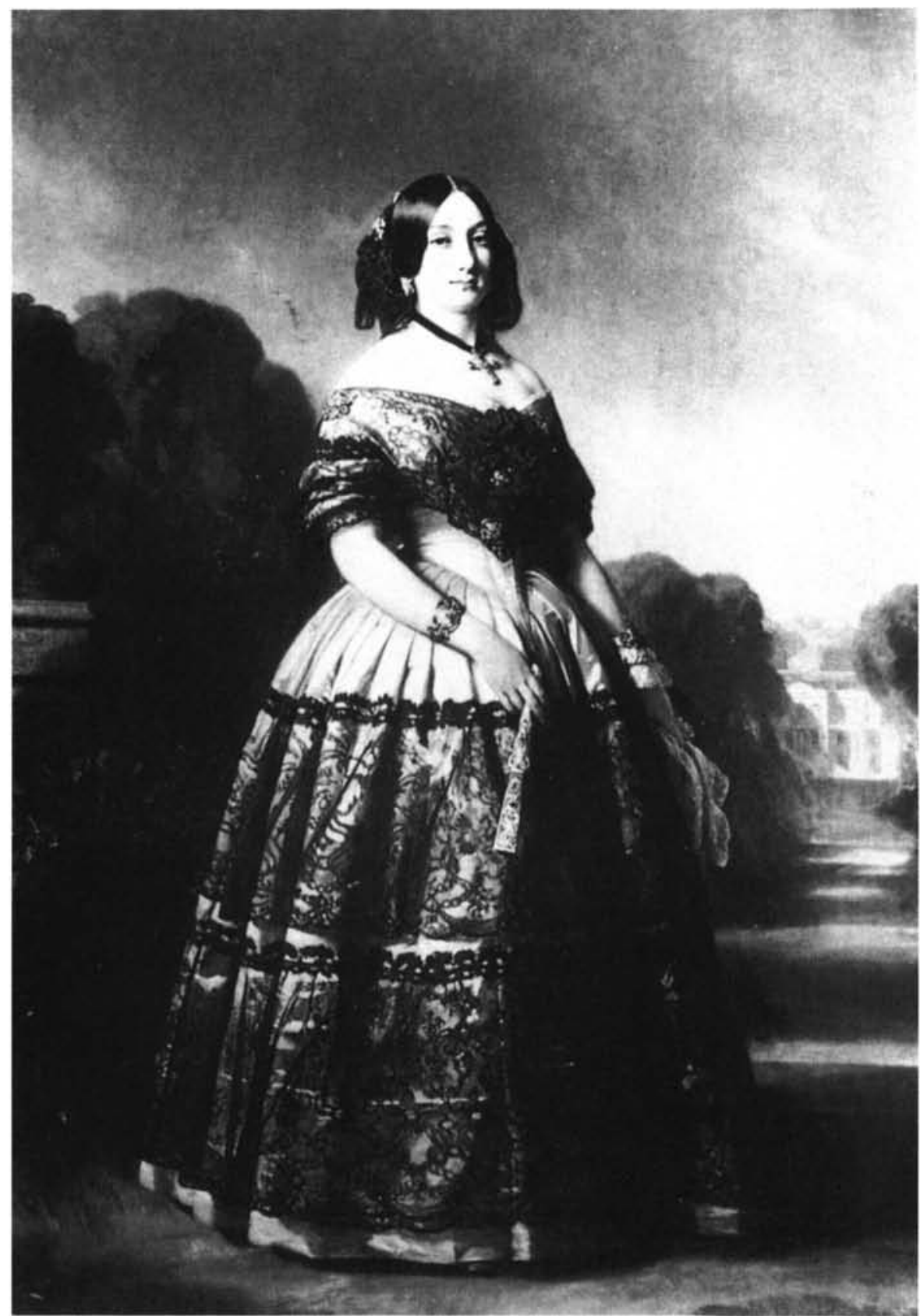

Foto 5: Franz Xaver Winterhalter. Duquesa de Montpensier, 1847. Óleo sobre lienzo. Medidas: $215 \times 136 \mathrm{cms}$. Colección particular. Versalles, Museo nacional del Castillo. 


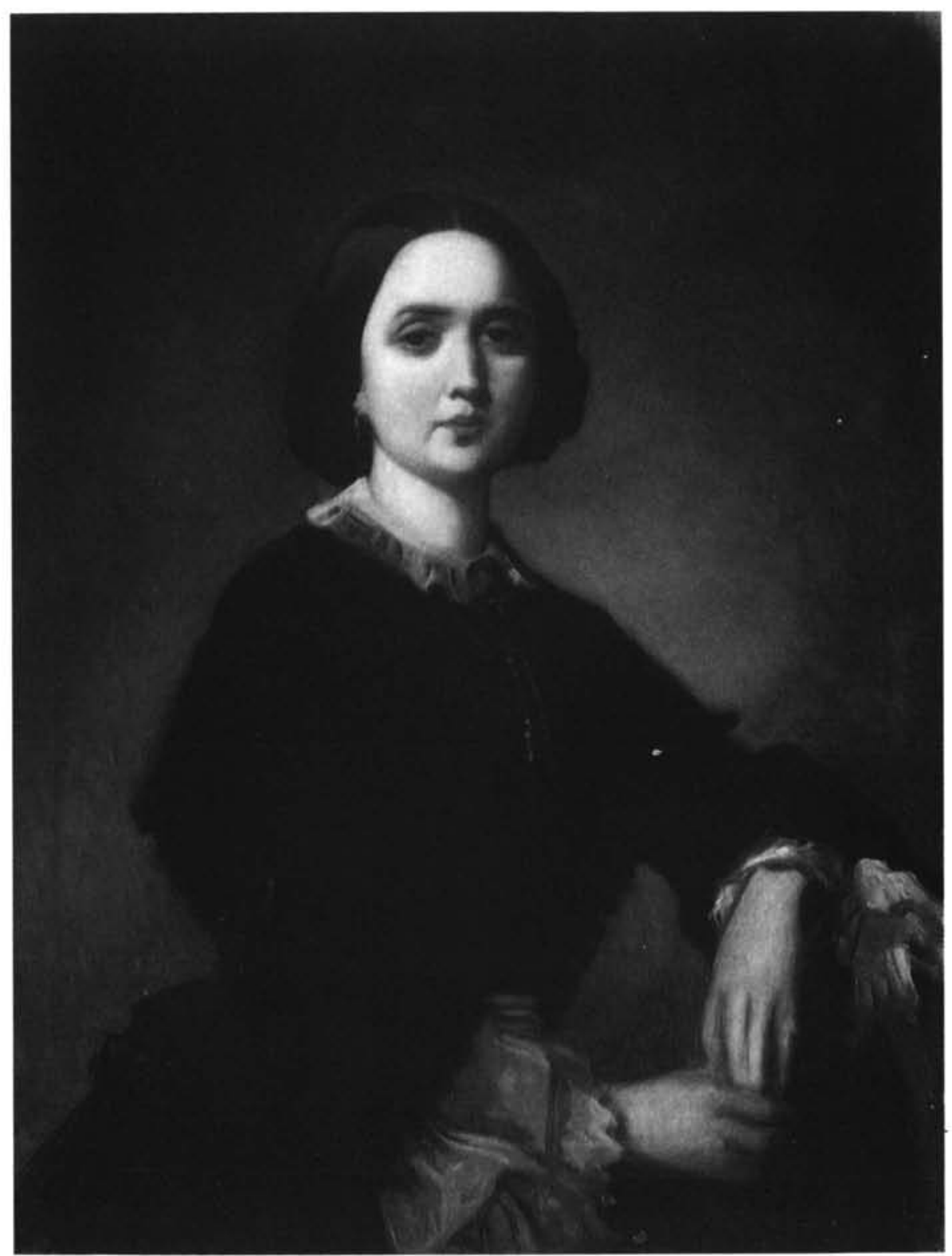

Foto 6: Federico de Madrazo. Sra. de Joaquín Domínguez Bécquer. Óleo sobre lienzo. Medidas: 90x69 cms. Museo Romántico. Madrid, inv. $\mathrm{n}^{\circ} 2301$. 